\title{
Towards a cross-neglected tropical disease perception study toolkit: a prototype toolkit developed in the field of leprosy
}

\author{
Anna T. van 't Noordende ${ }^{\mathrm{a}, \mathrm{b}} \&$ Wim H. van Brakel ${ }^{\mathrm{a}}$ \\ ${ }^{a}$ NLR, Wibautstraat 137K, 1094 DN Amsterdam, The Netherlands \\ ${ }^{\mathrm{b}}$ Erasmus MC, University Medical Center, Doctor Molewaterplein 40, \\ 3015 GD Rotterdam, The Netherlands
}

Submitted 1 April 2021; Accepted 22 April 2021

\begin{abstract}
Summary
Objectives: A negative perception of leprosy and other neglected tropical diseases (NTDs) is a problem that is seen globally. It results in discrimination, social exclusion and widespread mental health problems. There is a need for a standardised toolkit to assess the different aspects of perception of leprosy or other NTDs, including essential knowledge of these conditions.

Methods: We developed the Perception Study Toolkit (PST). This toolkit consists of four measures, a Communication Needs Assessment questionnaire, Knowledge Attitudes and Practices questionnaire, the EMIC community stigma scale and the Social Distance Scale. It also comprises qualitative methods to investigate perception: the way people see leprosy, what they know about leprosy and their attitudes, beliefs and reported behaviour towards persons affected by leprosy. The PST is a toolkit and comprises separate instruments that assess different aspects of perception, it is also possible to use only one or a few of the instruments of the PST.

Results: This is not applicable because this is not a study.

Conclusions: The PST can help identify specific beliefs, knowledge gaps, misconceptions and fears to inform community education and behaviour change interventions and can be used to monitor and evaluate such interventions. Using a standard toolkit like the PST would enable assessment of the perception of leprosy or other NTDs that would allow comparison across projects and countries including monitoring of changes over time.
\end{abstract}

Keywords: Leprosy, social aspects, stigma, attitude, NTD

Correspondence to: Anna T. van ’t Noordende (e-mail: a.vt.noordende@nlrinternational.org) 


\section{Introduction}

Leprosy is an infectious neglected tropical disease (NTD) that primarily affects the peripheral nerves and skin. If left untreated or detected late, leprosy may lead to severe visible and permanent disabilities. ${ }^{1,2}$ Persons affected by leprosy often experience stigma and discrimination, especially if they have visible impairments due to their condition. . $^{3,4}$

Health-related stigma refers to a negative social response to a disease. Stigma exists 'when elements of labelling, stereotyping, separation, status loss, and discrimination co-occur in a power situation that allows the components of stigma to unfold'. ${ }^{5}$ Discrimination is enacted stigma, it is acting on negative attitudes. ${ }^{5,6}$ Stigma does not always have to result in discrimination (e.g. people who have negative feelings or attitudes towards a person or group, but who do not act on this). Discrimination may also be caused or aggravated by other factors (e.g. fear, racism, sexism). ${ }^{6}$

Stigma and discrimination affect and disrupt many areas of a person's life, such as family and social life, social participation and mental well-being. ${ }^{4,7-10}$ Disabilities due to the condition may cause similar effects. Leprosy causes disability and is severely stigmatised. As a result, persons affected by leprosy may suffer depression, anxiety, suicide (attempts), mental distress, low self-esteem and low quality of life. ${ }^{11}$ Because of disability, stigma and poor mental health, they often experience social participation restrictions such as barriers to employment and social life, education or marriage. ${ }^{12}$ This may impose a social and economic burden on already marginalised families. ${ }^{9,13}$ Family members and friends may also experience stigma and discrimination. ${ }^{11}$ In addition, a negative perception of leprosy makes people reluctant to seek treatment, which may result in a delay in diagnosis or cure, increasing the risk of impairments that otherwise would have been prevented. ${ }^{2}$ Stigma is also a barrier to case finding and treatment adherence, and therefore timeliness and effectiveness of treatment. ${ }^{7,14,15}$

Perception is how individuals or groups "see" an object, person, event or institution. . $^{16}$ Perception is a broad concept; it may refer to how an individual or group "sees" others (social perception $)^{16,17}$ but also refers to a person's interpretation and understanding of a disease and its potential consequences (disease or illness perception). ${ }^{18}$ Perception comprises knowledge, beliefs, attitudes and emotions, which in turn influence and are influenced by personal factors (e.g. personality, experience) and environmental factors (e.g. culture, religion). ${ }^{16,17}$ Perceptions about leprosy, such as knowledge, attitudes and cultural beliefs, play an important role in stigma and early case finding. ${ }^{14,19-28}$ For example, people's knowledge influences their awareness that signs and symptoms are due to leprosy which, if awareness is lacking, hampers early reporting of leprosy. ${ }^{29-31}$ In addition, community attitudes towards persons affected by leprosy are strongly influenced by local misconceptions, cultural and religious beliefs and fears that may be linked to this. For example, in some cultures leprosy is linked to supernatural causes, witchcraft, sins or immoral behaviour, or believed to be hereditary. ${ }^{19,22,26,28,29}$ These misconceptions and beliefs are often different in different cultures and countries. Understanding these, as well as local knowledge gaps, is crucial to understand explanatory models, attitudes and behaviour. ${ }^{29,32}$

Efforts to address stigma and discrimination have focused on a number of areas including the stigmatised person, the stigmatising context and policy and systems. ${ }^{33,34}$ Positive outcomes in terms of reduced stigma have been reported for interventions like peer counselling, ${ }^{35-37}$ direct contact interventions such as community meetings, and indirect contact such as participatory videos and comics. ${ }^{37-40}$ For interventions to be effective, i.e. to increase positive attitudes and acceptance of persons affected by leprosy, it is important that they are culture-specific and address local beliefs and knowledge gaps. ${ }^{32}$ Only by understanding and addressing these 
local beliefs and perceptions, can we design effective public messages about leprosy and other interventions. Much leprosy-related suffering can be prevented by positively influencing the perception of leprosy and by reducing or eliminating stigma.

Many knowledge, attitudes and practices (KAP) surveys and stigma studies have been conducted. These studies have used a variety of tools: in-depth interviews and/or focus group discussions, validated questionnaires or questionnaires developed specifically for the study. At least 33 studies have developed their own questionnaire to assess knowledge about leprosy ${ }^{24,41-44}$ or knowledge, attitudes and practices about leprosy. ${ }^{20,22,27,28,45-68}$ These questionnaires are often not described well or not included in the articles. The field of leprosy would benefit from having more standardised tools, also for assessing the perception of leprosy to be able to measure progress and compare between projects.

Recently, 'leprosy perception studies' were conducted in endemic districts in Brazil, India, Nepal and Indonesia. ${ }^{26,69-72}$ The purpose of these studies was to investigate the perceptions regarding leprosy, i.e., the way people see leprosy, what they know about leprosy and their attitudes, beliefs, fears and reported behaviour towards persons affected by leprosy. Information of these studies is used to develop context-specific community education and behaviour change interventions that are implemented to raise awareness about leprosy and to improve knowledge, attitudes and behaviour towards (persons affected by) leprosy in the context of the $\mathrm{PEP}++$ project, a cluster-randomised trial to test an enhanced regimen for postexposure prophylaxis against leprosy. The objective of this paper is to describe the Perception Study Toolkit (PST), which was used in the PEP++ project, to implement 'perception studies' for the assessment and monitoring of knowledge, attitudes and practices regarding leprosy. We propose that the PST could form the basis for developing a standard toolkit to assess perception of leprosy and, with minor adaptations, other NTDs that would enable comparison across projects, countries and would allow monitoring of changes over time. We are not aware of an alternative toolkit to measure perception that is used in the field of NTDs.

\section{Material and methods}

\section{PURPOSE OF THE PERCEPTION STUDY TOOLKIT}

The purpose of the PST is to investigate the perceptions regarding leprosy: the way people see leprosy, what they know about leprosy and their attitudes, beliefs, fears and reported behaviour towards persons affected by leprosy. With minor adaptations, the PST can also be used for other NTDs. It should be noted that the PST is a toolkit and not one instrument with different subscales (it is not intended to calculate an overall score). The PST comprises separate instruments that assess different aspects of perception, it is also possible to use only one or a few of the instruments of the PST, depending on the purpose of the study.

\section{CONTENT OF THE PERCEPTION STUDY TOOLKIT}

The PST comprises questions to assess knowledge regarding key aspects of leprosy, such as what patients were told about their diagnosis, how they would prefer to call the disease, what people believe to be early symptoms and causes of leprosy, how it transmitted, whether it can be treated, etc. Perceived attitudes, behaviours and fears regarding leprosy in the community are explored and measured using the EMIC Community Stigma Scale (EMIC-CSS) and the Social Distance Scale (SDS). In addition, semi-structured interviews and focus group discussions are held to obtain an in-depth perspective to complement and help interpret the quantitative data. 
Table 1. Instruments included in the Perception Study Toolkit

\begin{tabular}{|c|c|c|}
\hline Tool & Type of tool & Purpose of tool \\
\hline Demographic information form & Form & $\begin{array}{l}\text { To collect basic participant } \\
\text { information such as name, age, } \\
\text { gender, address, occupation and } \\
\text { education }\end{array}$ \\
\hline KAP Questionnaire & Questionnaire & $\begin{array}{l}\text { To assesses knowledge, attitudes } \\
\text { and beliefs of individuals regarding } \\
\text { leprosy }\end{array}$ \\
\hline $\begin{array}{l}\text { Explanatory Model Interview } \\
\text { Catalogue Community Stigma } \\
\text { Scale (EMIC-CSS) }\end{array}$ & Scale & $\begin{array}{l}\text { To assess perceived attitudes and } \\
\text { behaviour towards affected persons } \\
\text { of community members in general }\end{array}$ \\
\hline Social Distance Scale (SDS) & Scale & $\begin{array}{l}\text { To assess how close a contact or } \\
\text { relationship a respondent is willing } \\
\text { to have to a person affected by } \\
\text { leprosy as a proxy for their attitudes }\end{array}$ \\
\hline $\begin{array}{l}\text { Communication Needs } \\
\text { Assessment (CNA) questionnaire }\end{array}$ & Questionnaire & $\begin{array}{l}\text { To assess what means of } \\
\text { communication people are using, } \\
\text { what means they are familiar with } \\
\text { and what means they find most } \\
\text { acceptable }\end{array}$ \\
\hline Semi-structured interviews & In-depth interview & $\begin{array}{l}\text { To establish an in-depth } \\
\text { conversation and understanding } \\
\text { regarding perceptions towards } \\
\text { leprosy }\end{array}$ \\
\hline Focus group discussions (FGDs) & Focus group discussion & $\begin{array}{l}\text { To provide a broad and diverse } \\
\text { spectrum of opinions and ideas on } \\
\text { knowledge and perceptions towards } \\
\text { leprosy. }\end{array}$ \\
\hline
\end{tabular}

Demographic data are also obtained from all participants. Each instrument is briefly described below. An overview can be found in Table 1 .

\section{Demographic information}

A demographic information form can be used to collect basic participant information such as name, age, gender, address, occupation and education. It is important to collect data on factors that may influence perception of leprosy or for practical reasons such as follow-up or dissemination of results.

\section{KAP questionnaire}

The 17-item KAP questionnaire assesses knowledge, attitudes and beliefs of individuals regarding leprosy. The questionnaire consists of yes/no/don't know questions and multiple answer questions. Topics include perception regarding cause and treatment of the disease, emotions after hearing the diagnosis and the emotions and attitudes of family, friends and neighbours towards leprosy. All questions are open ended, it is therefore important not to read out the answer options. Eight items on the KAP questionnaire can be used to assess knowledge of leprosy, to calculate a total knowledge score. On some of the questions, multiple answers are possible. A total score of nine can be obtained on the KAP when considering answers correct if the correct answers were given regardless of any incorrect answers. 'Adequate knowledge' is defined as a score of six or more out of nine on the KAP ( $>67 \%$ correct), 'moderate knowledge' 
as a score between 3 and 6 (33-67\% correct) and 'poor knowledge' as a score of three or less ( $<33 \%$ correct) on the KAP questionnaire. The KAP questionnaire has been used in several leprosy studies in India, Nepal, Indonesia and Brazil between 2012 and 2019, reports of four of these studies have been published to date. ${ }^{26,69,70,72}$

\section{EMIC community stigma scale}

The 15-item Explanatory Model Interview Catalogue Community Stigma Scale (EMIC-CSS) measures perceived attitudes and behaviour towards affected persons of community members in general. The EMIC-CSS covers areas of life that may be affected by stigma, such as concealment, avoidance, pity, shame, being made fun of, respect and marriage (prospects). During the interview, the participant is asked to respond to 15 questions, offering four response options that are valued with different scores: yes (2), possibly (1), no (0) and don't know (0). The EMIC-CSS total score ranges from zero (no negative attitudes) to 30 (most negative attitudes). The EMIC-CSS has been validated among community members of persons affected by leprosy in Brazil, India, Nepal and Indonesia. ${ }^{24,73-75}$

\section{Social distance scale}

The 7-item Social Distance Scale (SDS) measures how close a contact or relationship a respondent is willing to have to a person affected by leprosy as a proxy for their attitudes. The interviewee will start the SDS by reading the gender-specific vignette, a short description or word picture of a person with leprosy (separate for men and women). The vignette is followed by seven questions concerning the person in the vignette. The participant can respond to the questions by choosing one of the four options which are valued with different scores, i.e. definitely willing (0), probably willing (1), probably not willing (2) or definitely not willing (3). The SDS total score ranges from zero (no negative attitudes or fear) to 21 (most negative attitudes/fear). The SDS has been validated among community members of persons affected by leprosy in Indonesia. ${ }^{74}$ The SDS has not been formally validated for use with persons affected by leprosy in India, but has been translated to Hindi, and partially validated and used in studies in Uttar Pradesh and Dadra \& Nagar Haveli, India. ${ }^{69,70}$

\section{Communication needs assessment}

The 7-item Communication Needs Assessment (CNA) questionnaire is used to assess what means of communication people are using, what means they are familiar with and what means they find most acceptable. The results are used to inform the choice of media when designing education and behaviour change interventions. All questions on the CNA are open ended. Since questions are context-specific, for example 'what TV programmes do you usually watch?', the answer options should be adjusted according to make them appropriate for the context they are being used in. The CNA is only used when the PTS is used to develop community education and behaviour change interventions, as input/inventory of communication preference.

\section{Semi-structured interviews}

The aim of the semi-structured interviews is to establish an in-depth conversation regarding perceptions towards leprosy. The interview guide provides the interviewer with a clear layout of the interview and, depending on type of respondent, consists of 10-15 open questions.

\section{Focus group discussions}

Focus group discussions provide a broad and diverse spectrum of opinions and ideas on knowledge, sources of knowledge and reasons behinds certain views and perceptions and 
allows checking of views expressed by individuals or ranking of e.g. perceived frequency of opinions about components of perception or causative factors. During the focus group, the facilitator will use a question and topic guide as well as a timetable to conduct the discussion smoothly.

\section{EXPERIENCES WITH ITS USE}

The PST has been used in several studies in Brazil, India, Nepal and Indonesia already. ${ }^{26,69-72}$ The instruments can be used to investigate (gaps in) knowledge, specific fears, attitude and practices and to compare scores between participant groups, countries and in different points in time. Some examples of the use of the PST are provided below.

\section{Investigate and assess perceptions regarding leprosy}

Ballering and colleagues ${ }^{69}$ found that community members in Chandauli district in India had a more tolerant and accepting attitude when it comes to renting out a room to, being a colleague of or living next to a person cured from leprosy. At the same time and confirming findings from elsewhere, a majority of respondents were reluctant to have a person affected by leprosy as a caretaker of their children, or have a person affected by leprosy marry one of their children. ${ }^{69}$ The authors also report total scores on the KAP questionnaire, SDS and EMIC-CSS. ${ }^{69}$

\section{Interaction between knowledge, beliefs, attitudes and fears}

The PST has been used in a study in Fatehpur district, Uttar Pradesh, India, to examine the interaction between knowledge, beliefs, attitudes and fears. ${ }^{26}$ Using multivariate regression analysis, the authors found that health workers, participants who knew someone affected by leprosy, men, and participants with better knowledge of leprosy had more positive attitudes towards persons affected by leprosy. ${ }^{26}$ The authors also determined the factors that had an independent effect on knowledge and community stigma. These findings were later used as input for developing context-specific community education and behaviour change interventions ${ }^{76}$.

\section{Added benefit of using a mixed methods approach}

The study in Fatehpur district, India ${ }^{26}$ also illustrates the complementary nature of the in-depth interviews and focus group discussions. While the EMIC and SDS scales revealed negative attitudes and stigma towards persons affected by leprosy, the interviews provided in-depth insights in the reasons for exclusion. Avoidance of persons affected by leprosy was often linked to the belief that leprosy transmits by touch and (fear of) transmission. ${ }^{26}$ In addition, a study that used the PST in India, Nepal and Indonesia emphasised '(...) the importance of collecting both quantitative and qualitative data on a given topic, since results from the latter are often not generalisable' ${ }^{70}$

\section{Evaluation of an intervention}

Mieras and colleagues ${ }^{70}$ used the PST to assess the impact of the Leprosy Post-Exposure Prophylaxis (LPEP) project approximately one year after the start of its implementation in India, Nepal and Indonesia. They included persons affected by leprosy, close contacts and community members in each country before and after the start of the intervention. Their study provided insight in changes in KAP questionnaire, EMIC-CSS and SDS scores in each of these groups in the three countries. They found a significant increase in knowledge of leprosy (from 
$4 \%$ correct to $29 \%$ correct answers on the KAP questionnaire) and a decrease in SDS and EMIC-CSS stigma scores in community members in Nepal after the intervention. ${ }^{70}$

The implementation protocol of the PST, that comprises recommendations for using the toolkit in the field, can be found as additional information file 2 .

\section{Discussion}

This paper describes the Perception Study Toolkit. The toolkit consists of qualitative and quantitative (mixed) methods to allow for triangulation and provide rich data. This allows for a comprehensive understanding of the perception of leprosy. By using a standard toolkit to assess perception of leprosy, data can be compared across projects and countries, and progress can be monitored over time. We are not aware of an alternative toolkit to measure perception that is used in the field of NTDs.

We found 33 knowledge, attitudes and practices (KAP) surveys and stigma studies that developed their own questionnaire to assess knowledge about leprosy ${ }^{24,41-44}$ or knowledge, attitudes and practices about leprosy. ${ }^{20,22,27,28,45-68}$ These questionnaires were often not described well and were not included in the articles. The KAP questionnaire used in the PST Toolkit covers eight main topics: early symptoms, cause, mode of transmission, treatment, prevention, curability, contagiousness when on treatment and prevention of disabilities. The questions about curability and prevention have been added after consultation with leprosy experts, these two questions have not yet been pilot tested. We think the field of leprosy would benefit from having more standardised tools assessing the perception of leprosy and believe the KAP questionnaire could be such a standardised tool. We called the KAP questionnaire a questionnaire, because it has not been formally validated as a scale. This should be done in a future study, but we would first like to offer it to readers of this article for further improvement. Readers are invited to suggest further improvements to the KAP questionnaire.

Standardised tools used in other KAP or stigma studies are the EMIC-CSS $23,24,28,37,41,44,77$ and de SDS. ${ }^{23,37}$ The EMIC-CSS and SDS are also included in the PST. Since the EMIC-CSS questions are phrased in a more general way (for example 'would leprosy be a problem for a person to get married?') and the SDS questions are directed to the responded personally (for example how [would you feel about] about having one of your children marry someone like [name of person affected]?'), using both the EMIC-CSS and the SDS allows for the exploration of community and personal attitudes towards persons affected by leprosy. Interestingly, some studies using KAP or stigma surveys among persons affected by leprosy have also included tools to assess perceived or internalised stigma or social participation. The Participation Scale, ${ }^{23,78-80}$ which measures social participation, an outcome directly affected by stigma, and the EMIC stigma scale for affected persons ${ }^{42,79,80}$ have most frequently been used, followed by the Internalized Stigma of Mental Illness scale, ${ }^{23,80}$ the Jacoby stigma scale, ${ }^{79}$ Discrimination Assessment Form ${ }^{79}$ and the Leprosy Dehabilitation Scale. ${ }^{81}$ Even though the KAP questionnaire in the PST contains five questions about stigma for persons affected, we believe the PST would benefit from adding a tool to assess internalised and/or perceived stigma. The EMIC affected persons (EMIC-AP) ${ }^{82}$ would allow for comparison with the EMIC-CSS, given the similarities in the questions asked in the EMIC-AP and the EMIC-CSS. An alternative would be the Anticipated stigma subscale (4 items) and Internalised stigma subscale (6 items) of the SARI Stigma Scale. ${ }^{83}$

Besides assessing and monitoring knowledge, attitudes and practices regarding leprosy, the toolkit can also be used to develop culture-specific messages for health education, and to evaluate the impact of interventions. Even though low knowledge of leprosy has been 
associated with high levels of stigma, ${ }^{20,24,26-28}$ high levels of knowledge alone do not lead to more positive attitudes and behaviour towards persons affected by leprosy. ${ }^{84}$ Understanding the cultural belief systems in countries where leprosy is endemic is essential to understand and challenge stigma. ${ }^{85}$ Interviews with the target group to understand where behaviour comes from are crucial when developing interventions to change behaviour. ${ }^{86}$ A protocol that is often used to develop behaviour change interventions is intervention mapping. Intervention mapping is a six-step protocol that describes the path from problem identification to problem mitigation or problem solving. ${ }^{87}$ The PST covers step one to three of intervention mapping: a needs assessment or problem analysis and identifying which beliefs should be targeted (KAP, EMICCSS, SDS and interviews) and exploring media that fit the context of the target group (CNA). To our knowledge, 'communication needs assessments' are not often done in the leprosy field, when designing interventions for behaviour change. ${ }^{88}$ Step four to six of intervention mapping deal with drafting materials and designing implementation and evaluation plans. ${ }^{87}$

Determining whether changes pre- and post-intervention can be attributed to the intervention is challenging. We have listed several strategies to best deal with this in our recommendations for implementation (additional file 2). These strategies include appropriate timing of assessments, including a control group, cluster randomisation, adding specific questions about involvement in interventions in the follow-up assessment and implementing interventions step-wise if multiple interventions are implemented. The amount of time that should have elapsed since the intervention before it is evaluated depends on the type of intervention that is evaluated. Given that long-term effects are often desired, at least one year after the intervention implementation was completed would seem a reasonable period.

Readers are invited to suggest further improvements to the toolkit. Recommendations for the implementation of the toolkit in the field can be found as additional file (S2).

\section{Review board approval}

Not applicable because this was not a separate study. However, the PST has been approved several times by ethical review boards for studies in India, Nepal, Indonesia and Brazil.

\section{Acknowledgements}

We want to thank Dr. Liesbeth Mieras from NLR for proofreading and improving the final draft of this manuscript.

\section{Conflict of interest statement}

The authors report no conflict of interest.

\section{Funding}

The authors received no specific funding for this work.

\section{Authors' contributions}

AvtN and WB conceived the research and designed the methods. AvtN wrote the manuscript. WB edited the manuscript. Both authors read and approved the final manuscript. AvtN is guarantor of the manuscript. 


\section{Patient consent statement}

No patient consent was required.

\section{Data sharing statement}

Data sharing is not applicable to this article as no datasets were generated or analysed during the current study. The Perception Study Toolkit is available in Additional file 1. An implementation protocol is available in Additional file 2.

\section{Supplementary data}

Supplemental information for this article can be found online at https://doi.org/10.47276/lr.92.2.170.

\section{References}

1 Lastória JC, de Abreu MAMM. Leprosy: review of the epidemiological, clinical, and etiopathogenic aspectspart 1. An Bras Dermatol, 2014; 89(2): 205-218.

2 Suzuki K, Akama T, Kawashima A, Yoshihara A, Yotsu RR, Ishii N. Current status of leprosy: epidemiology, basic science and clinical perspectives. J Dermatol, 2012; 39(2): 121-129.

3 Navon L. Beggars, metaphors, and stigma: a missing link in the social history of leprosy. Soc Hist Med, 1998; 11(1): 89-105.

4 Adhikari B, Kaehler N, Raut S, Marahatta SB, Ggyanwali K. Risk factors of stigma related to leprosy-A systematic review. J Manmohan Meml Inst Heal Sci, 2013; 1(2): 3-11.

5 Link BG, Phelan JC. Conceptualizing stigma. Annu Rev Sociol, 2001; 27(1): 363-385.

6 Deacon H. Understanding HIV/AIDS Stigma: A Theoretical and Methodological Analysis. Cape Town: HSRC Press, 2005.

7 Van Brakel WH. Measuring health-related stigma-a literature review. Psychol Health Med, 2006; 11(3): 307-334.

8 Heijnders ML. The dynamics of stigma in leprosy. Int J Lepr, 2004; 72: 437-447.

9 van 't Noordende AT, Aycheh MW, Schippers A. The impact of leprosy, podoconiosis and lymphatic filariasis on family quality of life: A qualitative study in Northwest Ethiopia. PLoS Negl Trop Dis, 2020; 14(3): e0008173.

10 van 't Noordende AT, van Brakel WH, Banstola N, Dhakal KP. The impact of leprosy on marital relationships and sexual health among married women in eastern Nepal. J Trop Med, 2016; 2016: 88-96

11 Somar PMW, Waltz MM, van Brakel WH. The impact of leprosy on the mental wellbeing of leprosy-affected persons and their family members-a systematic review. Glob Ment Heal, 2020; 7: 1-19

12 Hofstraat K, van Brakel WH. Social stigma towards neglected tropical diseases: a systematic review. Int Health, 2016; 8(suppl. 1): i53-70.

13 Awofeso N. Stigma and socio-economic reintegration of leprosy sufferers in Nigeria. Acta Leprol, 1996; 10(2): 89-91.

14 Sermrittirong S, Van Brakel W. Stigma in leprosy: concepts, causes and determinants. Lepr Rev, 2014; 85: 36-47.

15 Heijnders ML. Experiencing leprosy: perceiving and coping with leprosy and its treatment. A qualitative study conducted in Nepal. Lepr Rev, 2004; 75(4): 327-337.

16 Pickens J. Attitudes and perceptions. Organ Behav Heal care, 2005; 4(7): 43-76

17 Hiebert PG. Transforming Worldviews: An Anthropological Understanding of How People Change. Grand Rapids, Michigan, US: Baker Academic, 2008.

18 Broadbent E, Wilkes C, Koschwanez H, Weinman J, Norton S, Petrie KJ. A systematic review and meta-analysis of the Brief Illness Perception Questionnaire. Psychol Health, 2015; 30(11): 1361-1385.

19 Ebenso B, Newell J, Emmel N, Adeyemi G, Ola B. Changing stigmatisation of leprosy: an exploratory, qualitative life course study in Western Nigeria. BMJ Glob Heal, 2019; 4(2): e001250.

20 Seshadri D, Khaitan BK, Khanna N, Sagar R. The tangled web: a study of knowledge and attitude towards leprosy from a tertiary care hospital in India. Indian J Lepr, 2014; 86: 27-41.

21 Sottie CA, Darkey J. Living with stigma: Voices from the Cured Lepers' village in Ghana. Soc Work Health Care, 2019; 58(2): 151-165.

22 Tabah EN, Nsagha DS, Bissek A-CZ-K, Njamnshi TN, Njih IN-N, Pluschke G et al. Community knowledge, perceptions and attitudes regarding leprosy in rural Cameroon: The case of Ekondotiti and Mbonge health districts in the South-west Region. PLoS Negl Trop Dis, 2018; 12(2): e0006233. 
23 Ibikunle PO, Nwokeji SC. Assessment of stigma among people living with Hansen's disease in south-east Nigeria. Lepr Rev, 2017; 88: 43-57.

24 Adhikari B, Shrestha K, Kaehler N, Raut S, Chapman SR. Community attitudes towards leprosy affected persons in Pokhara municipality of western Nepal. J Nepal Health Res Counc, 2014; 11(25): 264-268

25 Tekle-Haimanot R, Forsgren L, Gebre-Mariam A, Abebe M, Holmgren G, Heijbel J et al. Attitudes of rural people in central Ethiopia towards leprosy and a brief comparison with observations on epilepsy. Lepr Rev, 1992; 63(2): 157-168.

26 van 't Noordende AT, Korfage I, Lisam S, Arif MA, Kumar A, van Brakel WH. The role of perceptions and knowledge of leprosy in the elimination of leprosy: A baseline study in Fatehpur district, northern India. PLoS Negl Trop Dis, 2019; 13(4): e0007302.

27 van den Broek J, O’Donoghue J, Ishengoma A, Masao H, Mbega M. Evaluation of a sustained 7-year health education campaign on leprosy in Rufiji District, Tanzania. Lepr Rev, 1998; 69(1): 57-74.

28 Singh R, Singh B, Mahato S. Community knowledge, attitude, and perceived stigma of leprosy amongst community members living in Dhanusha and Parsa districts of Southern Central Nepal. PLoS Negl Trop Dis, 2019; 13(1): e0007075.

29 Opala J, Boillot F. Leprosy among the Limba: illness and healing in the context of world view. Soc Sci Med, 1996; 42(1): 3-19.

30 Da Silva Souza C, Bacha JT. Delayed diagnosis of leprosy and the potential role of educational activities in Brazil. Lepr Rev, 2003; 74: 249-258.

31 Robertson LM, Nicholls PG, Butlin R. Delay in presentation and start of treatment in leprosy: experience in an out-patient clinic in Nepal. Lepr Rev, 2000; 71(5): 511-516.

32 Brown W. Can social marketing approaches change community attitudes towards leprosy? Lepr Rev, 2006; 77(2): 89-98.

33 Cook JE, Purdie-Vaughns V, Meyer IH, Busch JTA. Intervening within and across levels: A multilevel approach to stigma and public health. Soc Sci Med, 2014; 103: 101-109.

34 Van't Noordende AT, Kuipers P, Pereira ZBD. Strengthening personal and family resilience: a literature review for the leprosy context. Lepr Rev, 2019; 90(1): 88-104.

35 Lusli M, Peters RMH, Zweekhorst MB, Van Brakel WH, Seda FS. Lay and peer counsellors to reduce leprosyrelated stigma-lessons learnt in Cirebon, Indonesia. Lepr Rev, 2015; 86: 37-53.

36 Lusli M, Peters R, van Brakel W, Zweekhorst M, Iancu S, Bunders J et al. The impact of a rights-based counselling intervention to reduce stigma in people affected by leprosy in Indonesia. PLoS Negl Trop Dis, 2016; 10(12): e0005088.

37 Dadun D, Van Brakel WH, Peters RMH, Lusli M, Zweekhorst M, Bunders JGF et al. Impact of socio-economic development, contact and peer counselling on stigma against persons affected by leprosy in Cirebon, Indonesia-a randomised controlled trial. Lepr Rev, 2017; 88: 2-22.

38 Peters RMH, Zweekhorst MBM, Bunders JFG, van Brakel WH. A cluster-randomized controlled intervention study to assess the effect of a contact intervention in reducing leprosy-related stigma in Indonesia. PLoS Negl Trop Dis, 2015; 9(10): e0004003.

39 Peters R, Lusli M, Zweekhorst M, Miranda-Galarza B, van Brakel W, Irwanto et al. Learning from a leprosy project in Indonesia: making mindsets explicit for stigma reduction. Dev Pract, 2015; 25(8): 1105-1119.

40 Peters RMH, Zweekhorst MBM, van Brakel WH, Bunders JFG, Irwanto. 'People like me don't make things like that': Participatory video as a method for reducing leprosy-related stigma. Glob Public Health, 2016; 11(5-6): 666-682.

41 Kaehler N, Adhikar B, Raut S, Marahatta SB, Chapman RS. Perceived stigma towards leprosy among community members living close to Nonsomboon leprosy Colony in Thailand. PLoS One, 2015; 10(6): e 0129086.

42 Adhikari B, Kaehler N, Chapman RS, Raut S, Roche P. Factors affecting perceived stigma in leprosy affected persons in western Nepal. PLoS Negl Trop Dis, 2014; 8(6): e2940.

43 Kar S, Ahmad S, Pal R. Current knowledge attitudes, and practices of healthcare providers about leprosy in Assam, India. J Glob Infect Dis, 2010; 2(3): 212.

44 Faatoese A, Sikaleti S, Priest P, Chambers S. Knowledge and attitudes to leprosy of Pacific People living in New Zealand. Lepr Rev, 2016; 87: 368-377.

45 Rao P V, Rao SL, Vijayakrishnan B, Chaudhary AB, Peril S, Reddy BP et al. Knowledge, attitude and practices about leprosy among medical officers of Hyderabad urban district of Andhra Pradesh. Indian J Lepr, 2007; 79(1): 27-43.

46 ØSTBYE T. Knowledge, attitudes and practices relating to leprosy among public health care providers in Colombo, Sri Lanka. Lepr Rev, 2017; 88: 75-84.

47 Grewal I, Negi Y, Kishore J, Adhish SV. Knowledge and attitude about Leprosy in Delhi in post elimination phase. Indian J Lepr, 2013; 85(93): 123-127 
48 Graciano-Machuca O, Velarde-de la Cruz EE, Ramírez-Dueñas MG, Alvarado-Navarro A. University students' knowledge and attitudes towards leprosy. J Infect Dev Ctries, 2013; 7(09): 658-664.

49 John AS, Rao OS. Awareness and attitudes towards leprosy in urban slums of Kolkata, India. Indian J Lepr, 2009; 81(3): 135-140.

50 Bajaj DR, Matlani BL, Soomro FR, Iqbal MP. Knowledge, attitude and practices regarding leprosy among general practitioners at Hyderabad. J Coll Physicians Surg Pak, 2009; 19(4): 215-218.

51 Chen S-M, Zhang L, Liu D-C, Liu H-X. Assessment of knowledge and skills in early diagnosis of leprosy and attitudes towards leprosy amongst doctors working in dermatological services, Shandong Province, People's Republic of China. Lepr Rev, 2004; 75(4): 348-356.

52 Briden A, Maguire E. An assessment of knowledge and attitudes towards leprosy/Hansen's disease amongst healthcare workers in Guyana. Lepr Rev, 2003; 74(2): 154-162.

53 Touko A, Kemmegne J, Nyiama T. Perception of lepers by non-lepers in an urban center in Cameroon. Sante, 1996; 6(5): 269-274.

54 Gittens C. Attitudes towards leprosy in the outpatient population of dermatology clinics in Trinidad. Lepr Rev, 1992; 63(2): 151-156.

55 Crook N, Ramasubban R, Samy A, Singh B. An educational approach to leprosy control: an evaluation of knowledge, attitudes and practice in two poor localities in Bombay. India. Lepr Rev, 1991; 62(4): 395-401.

56 Gerochi LN. Knowledge, beliefs and attitudes on leprosy in Iloilo City Proper, Philippines. Southeast Asian. J Trop Med Public Health, 1986; 17(3): 433-436.

57 Stephen T, Selvaraj I, Parameswari PJ. Assessment of knowledge, attitude and practice about leprosy among patients and their families in a rural community in Tamil Nadu. Indian J Lepr, 2014; 86(1): 7-14.

58 Awofeso N. Appraisal of the knowledge and attitude of Nigerian nurses toward leprosy. Lepr Rev, 1992; 63(2): 169-172

59 Danturty I, Manchala S, Jairaj S. Community based study of knowledge, attitude and practices towards leprosy in an urban slum in Secunderabad, Telangana. JMSCR, 2016; 49(11): 13527-13531.

60 Asnake MK, Ahmed M, Genebo T, Mekebib B. Knowledge and attitude of health professionals in relation to the integration of leprosy control into the general health service in Ethiopia. Int J Lepr other Mycobact Dis, 2000; 68(3): 299.

61 Urgesa K, Bobosha K, Seyoum B, Geda B, Weldegebreal F, Mihret A et al. Knowledge of and attitude toward leprosy in a leprosy endemic district, eastern ethiopia: a community-based study. Risk Manag Healthc Policy, 2020; 13: 1069 .

62 Tesema AA, Beriso M. Assessment of knowledge and attitude of community on leprosy patients in Kuyera Town, West Arsi Zone, Oromia Region Southeast Ethiopia. Hered Genet, 2015; 4(4): 156.

63 Jain M, Sharma A, Jain V, Virjee K, Singh S. Knowledge and attitude about leprosy among Indian dental students in Faridabad. J Clin diagnostic Res JCDR, 2016; 10(3): ZC48.

64 Mankar MJ, Joshi SM, Velankar DH, Mhatre RK, Nalgundwar AN. A comparative study of the quality of life, knowledge, attitude and belief about leprosy disease among leprosy patients and community members in Shantivan Leprosy Rehabilitation centre, Nere, Maharashtra, India. J Glob Infect Dis, 2011; 3(4): 378.

65 Barkataki P, Kumar S, Rao PS. Knowledge of and attitudes to leprosy among patients and community members: a comparative study in Uttar Pradesh, India. Lepr Rev, 2006; 77: 62-68.

66 Kumar R, Singhasivanon P, Sherchand JB, Mahaisavariya P, Kaewkungwal J, Peerapakorn S et al. Gender difference in socio-epidemiological factors for leprosy in the most hyper-endemic district of Nepal. Nepal Med Coll J NMCJ, 2004; 6(2): 98-105.

67 Croft RP, Croft RA. Knowledge, attitude and practice regarding leprosy and tuberculosis in Bangladesh. Lepr Rev, 1999; 70(1): 34-42.

68 Saha G, Mandal NK, Dutta RN. Current Perceptions and Practices (KAP) about leprosy among leprosy patients: A comparative study between high prevalent \& low prevalent districts of West Bengal. Indian J Lepr, 2015; 87(1): $1-16$

69 Ballering A V, Peters RMH, Waltz MM, Arif MA, Mishra CP, van Brakel WH et al. Community stigma and desired social distance towards people affected by leprosy in Chandauli District, India. Lepr Rev, 2019; 90(4): 418-432.

70 Mieras L, Singh MK, Manglani PR, Arif MM, Banstola NL, Pandey B et al. A single-dose of rifampicin to prevent leprosy; quantitative analysis of impact on perception, attitudes and behaviour of persons affected, contacts and community members towards leprosy in India, Nepal and Indonesia. Lepr Rev, 2020; 91: 314-327.

71 Peters R, Mieras L, Subedi M, Apte H, Koesbardiati T, Banstola NL et al. A single dose of rifampicin to prevent leprosy: qualitative analysis of perceptions of persons affected, contacts, community members and health professionals towards chemoprophylaxis and the impact on their attitudes in India, Nepal and Indonesia. Lepr Rev, 2018; 89(4): 335-352. 
72 van't Noordende AT, Lisam S, Ruthindartri P, Sadiq A, Singh V, Arifin M et al. Leprosy perceptions and knowledge in endemic districts in India and Indonesia: differences and commonalities. PLoS Negl Trop Dis, 2021; 15(1): e0009031.

73 Rensen C, Bandyopadhyay S, Gopal PK, Van Brakel WH. Measuring leprosy-related stigma-a pilot study to validate a toolkit of instruments. Disabil Rehabil, 2011; 33(9): 711-719.

74 Peters RMH, Van Brakel WH, Zweekhorst MBM, Damayanti R, Bunders JFG. The cultural validation of two scales to assess social stigma in leprosy. PLoS Negl Trop Dis, 2014; 8(11): e3274.

75 Oliveira HX. Adaptação transcultural das escalas de estigma Explanatory Model Interview Catalogue (EMIC) na perspectiva de pessoas acometidas pela hanseníase e da comunidade para o contexto brasileiro [Internet]. Universidade Federal do Ceará; 2018. Available from: http://www.repositorio.ufc.br/bitstream/riufc/39006/1/2 018_dis_hxoliveira.pdf.

76 van 't Noordende AT, Lisam S, Singh V, Sadiq A, Agarwal A, Hinders D, Richardus JH, van Brakel WH, and Korfage IJ. Changing perception and improving knowledge of leprosy: an intervention study in Uttar Pradesh, India. PLoS Negl Trop Dis (submitted)

77 Sermrittirong S, Van Brakel WH, Kraipui N, Traithip S, Bunders-Aelen JF. Comparing the perception of community members towards leprosy and tuberculosis stigmatization. Lepr Rev, 2015; 86(1): 54-61.

78 Sinha A, Kushwaha AS, Kotwal A, Sanghi S, Verma AK. Stigma in leprosy: Miles to go!. Indian J Lepr, 2010; 82(3): 137.

79 Van Brakel WH, Sihombing B, Djarir H, Beise K, Kusumawardhani L, Yulihane R et al. Disability in people affected by leprosy: the role of impairment, activity, social participation, stigma and discrimination. Glob Health Action, 2012; 5(1): 18394.

80 Stevelink SAM, Van Brakel WH, Augustine V. Stigma and social participation in Southern India: Differences and commonalities among persons affected by leprosy and persons living with HIV/AIDS. Psychol Health Med, 2011; 16(6): 695-707.

81 Roosta N, Black DS, Rea TH. A comparison of stigma among patients with leprosy in rural Tanzania and urban United States: a role for public health in dermatology. Int J Dermatol, 2013; 52(4): 432-440.

82 Weiss MG, Doongaji DR, Siddhartha S, Wypij D, Pathare S, Bhatawdekar M, Bhave A, Sheth A, and Fernandes R. The explanatory model interview catalogue (EMIC). The British Journal of Psychiatry, 1992; 160(6): 819830

83 Dadun, Peters RMH, Van Brakel W, Lusli M, Damayanti R, Bunders JFG et al. Cultural validation of a new instrument to measure leprosy-related stigma: the SARI stigma scale. Lepr Rev, 2017; 88: 23-42.

84 Wong ML. Guest editorial: designing programmes to address stigma in leprosy: issues and challenges. Asia Pacific Disabil Rehabil J, 2004; 15: 3-12.

85 Cross H. Interventions to address the stigma associated with leprosy: a perspective on the issues. Psychol Health Med, 2006; 11(3): 367-373.

86 Montano DE, Kasprzyk D. Theory of reasoned action, theory of planned behavior, and the integrated behavioral model. Heal Behav Theory, Res Pract, 2015; 70(4): 231.

87 Bartholomew LK. Intervention mapping: A process for developing theory-and evidence-based health education programs. Heal Educ Behav, 1998; 25(5): 545-563.

88 Lynch P. A new face for an old disease: some reflections on the role of the media in Nepal's first national leprosy elimination campaign. Lepr Rev, 2000; 71(1): 62-70. 